\title{
Resistance spot welding with variable electrode force-development and benefit of a force profile to extend the weldability of $22 \mathrm{MnB} 5+\mathrm{AS} 150$
}

\author{
M. Wohner ${ }^{1}(\mathbb{D}) \cdot$ N. Mitzschke ${ }^{1} \cdot$ S. Jüttner ${ }^{1}$ \\ Received: 29 May 2020 / Accepted: 21 September 2020 / Published online: 7 October 2020 \\ (C) The Author(s) 2020
}

\begin{abstract}
Compared with conventional steels, press-hardened steels with an aluminium-silicon coating have a smaller welding range, which is resulting in reduced process stability. For this reason, an analytical methodology is required, which can optimise the welding parameters and extend the welding range significantly. Consequently, most publications focus on the variation of welding time and welding current at a constant electrode force. This paper deals with the design of a force profile to improve weldability and joint quality. The basis for this investigation is the identification of significant characteristic values by the recorded process signals.
\end{abstract}

Keywords Variable electrode force $\cdot$ Force profile $\cdot$ Optimise welding parameters $\cdot$ Extend welding range

\section{Introduction}

Resistance spot welding (RSW) is one of the dominating welding processes in automotive production [1]. It can be explained by the fact that the RSW process is highly efficient and can be automatised [2]. A vehicle has on average 2000-5000 welding spots [2]. Furthermore, different coating concepts and materials are used $[2,3]$. This results in new challenges for resistance spot welding, such as joining of two press-hardened steels with an aluminium-silicon coating, which is used for patchwork blanks or hat profiles [3-7]. Compared with conventional steels, the press-hardened steels have a smaller welding range, which is reflected in an increased expulsion tendency and a decrease in process stability $[4,8-10]$. The welding parameters have a direct influence on the resistance spot welding process [11]. For this reason, it is important to adjust these parameters precisely to the specific material to achieve an increase in process stability. The welding parameters can be

Recommended for publication by Commission III - Resistance Welding, Solid State Welding, and Allied Joining Process

M. Wohner

maximilian.wohner@ovgu.de

1 Institute of Materials and Joining Technology,

Otto-von-Guericke-University of Magdeburg, Magdeburg, Germany optimised by various approaches, such as simulation, design of experiment or analysis of the process signals recorded during welding $[12,13]$. The present investigation is focused on the process data analysis. As a result, significant characteristic values for the design of a force profile are determined. The developed force profile should improve the weldability with a simultaneously increased joint quality.

\section{State of the art}

\subsection{Influence of the electrode force on the welding process}

The electrode force is a variable in the welding process, which affects between the electrode tips and is classified into a squeeze, welding and holding force $[11,15]$. The force is used to ensure a uniform current introduction into the joining elements. The level of the electrode force influences the resistivity in the circuit. Consequently, there is a change in the amount of generated heat, which is reflected in the nugget formation, as shown in Fig. 1. All shown simulations of electrode forces have the same welding current and the same welding time [14].

As shown in Fig. 1, lowering the electrode force increases the formation of the welding nugget and minimise the 


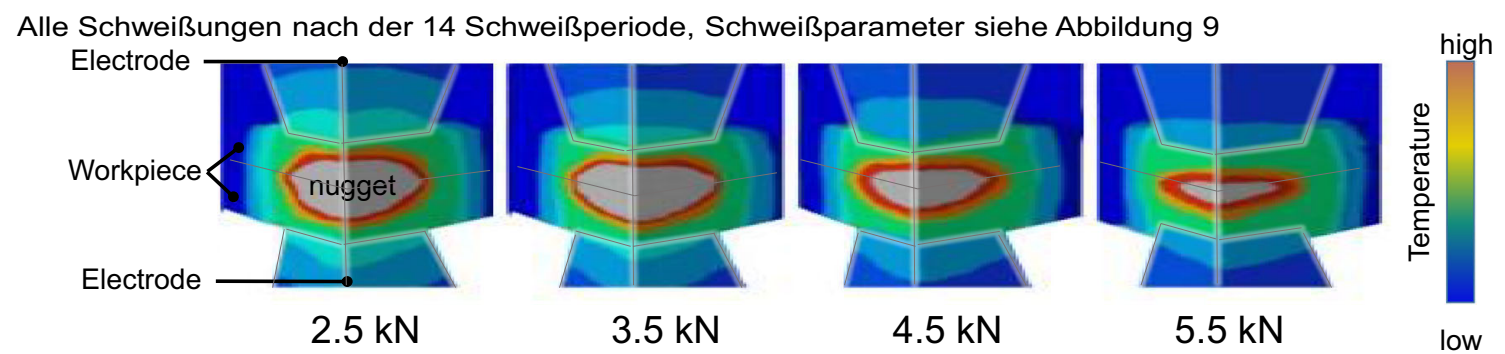

Fig. 1 Influence of the electrode force on the temperature distribution, according to [14]

indentation of the electrode into the material $[15,16]$. A possible consequence of maximising the nugget diameter by selecting a low electrode force is rejected in [14]. The reason is based on two opposing effects. (1) On the one hand, the current density increases by a low electrode force, which leads to earlier nugget formation [14]. (2) On the other hand, it results in a reduction of the contact area in the faying layer (sheet/sheet), which influences the maximum nugget width [14]. As a result of this compromise, the maximum nugget diameter is obtained at a specific electrode force [14]. Furthermore, it must be considered that a too low or high force [17-19] leads to an increase in the probability of expulsion and a reduction of the welding range [20]. A sufficient electrode force is also required to compensate for a gap between the sheets [21].

\subsection{Electrode force profiles}

In general, an electrode force profile is described as a variation of the force during the whole welding process [22-24]. In this case, the force level is adjusted and does not result from the stiffness of the used equipment [22]. In practice, increased electrode forces are used in the squeeze time [24]. This force profile approach is aimed to reduce the contact resistance and, therefore, to minimise welding expulsion in the initial welding time [25]. During the welding time, the electrode force can be classified into constant and variable progress. Both types influence the nugget formation and the occurrence of expulsion. Compared with welding current, which is widely used in the form of current programs and profiles, investigations of force profiles have been carried out only insufficiently. However, their influence, primarily in the welding time, is estimated to be the most significant $[11,25]$.

\subsection{Process data acquisition for resistance spot welding}

Process data analysis is the basis for various applications in resistance spot welding, such as quality monitoring and adaptive control of the RSW process [27]. For this purpose, process signals are required, which correlate with the nugget development and therefore allow a prediction about the achieved welding quality $[27,28]$. Various process signals can be recorded during the welding process, such as the mechanical parameters (electrode displacement, electrode force) and the electrical parameters of the welding process (voltage, current, resistance and energy) $[26,27,29]$. The sensitivity of these process signals to interfering effects is shown in Table 1.

A lot of information about the nugget development as well as the interfering effects are represented by the dynamic resistance, the power and the electrode displacement $[26,28$, $30-33]$.

\subsubsection{Dynamic resistance and welding power}

Dynamic resistance is the quotient of welding voltage and welding current during the welding process [34]. The welding power is calculated by multiplying the welding voltage and the welding current. Both the dynamic resistance curve and the power are used to monitor nugget development and detect weld expulsion and are used for quality and control variables $[26,30]$. The welding power can be measured partially by the voltage drops in the individual sheet layers [28]. By using this method, it is possible to determine the amount of energy input in the individual faying interfaces [28]. It is possible to detect the formation of the nugget more precisely compared with the full welding power [28].

\subsubsection{Electrode displacement}

The electrode displacement, which correlates with the thermal expansion of the specimen, has been the object of research for monitoring and controlling the welding process $[27,31-33$, 36]. The first approaches for evaluating weld quality are based on the maximum electrode movement and the initial expansion rate of the join partners [31,32,35]. This was used for the development of different control systems that utilise the electrode displacement and velocity as reference curves $[26,28$, 36-38]. Figure 2 shows the schematic electrode displacement as a function of the processing time.

In the first section (1), the squeeze force is built up, and the electrode displacement is referenced on this level. Following (2), a welding current is introduced, and due to the thermal expansion of the material, the electrodes are separated. After a certain point in time, the electrodes may sink into the material due to softening of the material [28]. In the third section (3), 
Table 1 Sensitivity of recorded quantities to interfering effects, according to [26]

\begin{tabular}{|c|c|c|c|c|c|c|}
\hline \multirow[t]{2}{*}{ Interfering effect } & \multicolumn{6}{|l|}{ Recorded signals } \\
\hline & Electrode displacement & Weld voltage & Welding current & Dynamic resistance & Welding power & Supplied energy \\
\hline Main fluctuation & + & + & + & + & + & + \\
\hline Shunting & + & + & & + & $(+)$ & \\
\hline Electrode wear & + & + & & + & + & + \\
\hline Heat removal & + & & & & & \\
\hline Expulsion & + & + & + & + & + & + \\
\hline Poor fitting & + & & & + & + & \\
\hline Thickness variation & + & + & + & + & + & + \\
\hline Number of sheets & + & + & + & + & + & \\
\hline Change of materials & + & & & + & + & \\
\hline
\end{tabular}

A plus (+) means that the interfering effect can be detected with the measured signals

the current shut off and a controlled cooling and contraction of the material occurs. This leads to a sinking of the electrode displacement. A visible indentation of the electrodes in the workpiece surface remains [31, 35].

\section{Experimental investigations}

\subsection{Approach of the investigations}

Figure 3 illustrates the approach of the investigations. First, the influence of a constant electrode force on the welding range was investigated. Simultaneously, the process data for each welding spot was recorded.

The target of the investigations is to increase the welding range and the tensile strength compared with the initial condition. In general, the welding current range is defined by the minimum spot diameter and the occurrence of expulsion. An extension of the welding range can be achieved by shifting the expulsion limit to higher welding currents. An optimisation can be done by a precise adjustment of the welding parameters. Therefore, a characteristic value from the process signals must be found, which allows a prediction of the expulsion.
The characteristic value is used for the analytical conception of a force profile to avoid early expulsion. After the conception of the force profile, the welding range and time-related nugget growth are compared with the initial welding parameter according to SEP 1220-2.

\subsection{Welding equipment, material and methodology}

\subsubsection{Welding equipment}

All welding experiments were carried out on a stationary Cframe welding machine. The welding current was generated by a $1 \mathrm{kHz}$ Mid-Frequency Direct Current (MFDC by Bosch PSI 6300) inverter with constant current control (CCC). The special feature of the resistance spot welding system is the force unit (magneticDrive ${ }^{\circledR}$ by NIMAK $\mathrm{GmbH}$ ). The upper electrode was positioned by a linear drive, whereas a magnetic force control unit realised the actual force generation. By this technology, it is possible to control the force of the electrode dynamically during the welding process and to design a force profile. During the welding process, four process signals were recorded synchronously. An MFDC inverter was used to output the current signal, while the voltage signal was taken
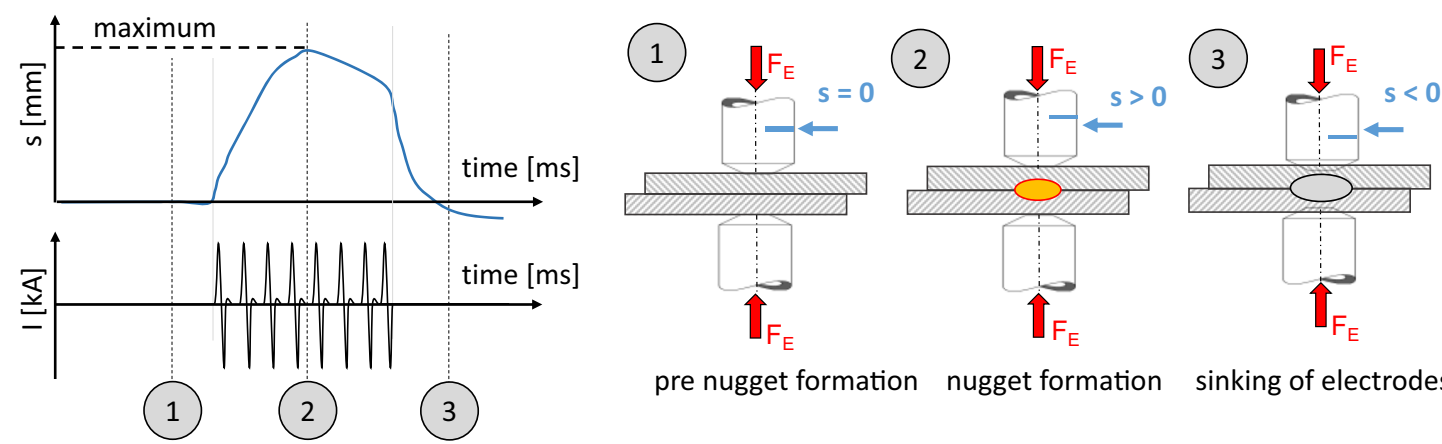

pre nugget formation nugget formation sinking of electrodes

Fig. 2 Schematic illustration of the electrode displacement, based on [31, 35] 


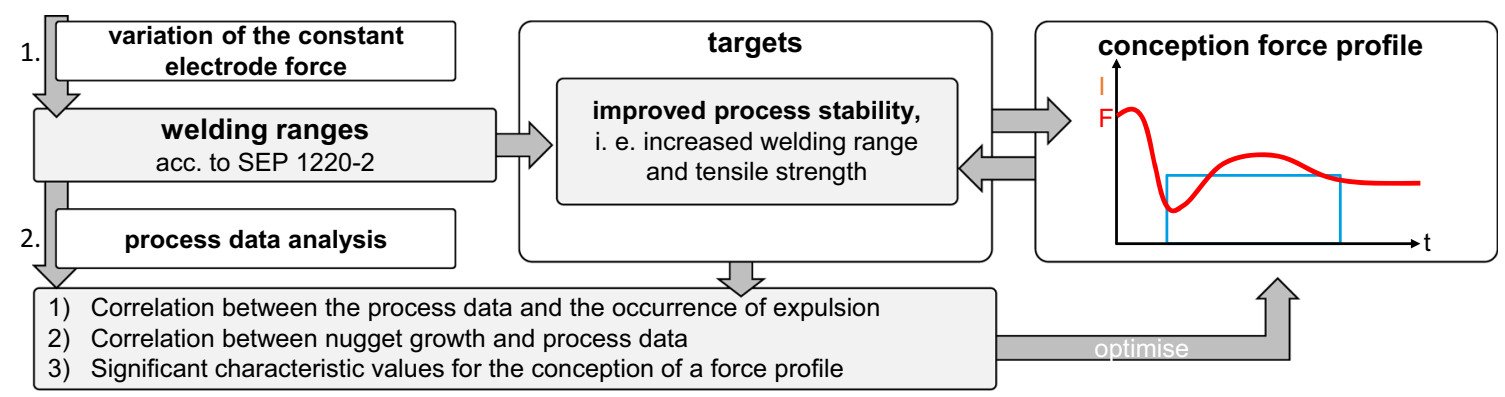

Fig. 3 Schematic illustration of the investigations

directly from the electrodes. A piezoelectric measuring sensor (Kistler AG) measured the electrode force. An absolute displacement encoder determined the electrode movement (GT2 - H12 by Keyence). Data recording was carried out at a sampling rate of $25.6 \mathrm{kHz}$ by the WeldQAS from HKSProzesstechnik GmbH. Subsequently, the individual process variables were smoothed by low-pass filters $(1000 \mathrm{~Hz})$.

\subsubsection{Material}

The investigations were carried out on press hardened $22 \mathrm{MnB} 5+\mathrm{AS} 150$ (material number: 1.5528) with an aluminium-silicon coating on both sides. The sheet thickness was in total $1.5 \mathrm{~mm}$, which was including the coating weight of $150 \mathrm{~g} / \mathrm{m}^{2}$. A furnace temperature of $900{ }^{\circ} \mathrm{C}$ and a duration time of 6 min were selected for the austenitic process of the sheet. After the furnace process was completed, the austenitised sheet was transferred to the forming tool. The forming tool (press) ensured a fast and controlled cooling of the material, which resulted in a complete martensitic structure of the weld specimens with a hardness of about 480 HV1.

\subsubsection{Methods for determining weldability}

Electrode tips from $\mathrm{CuCr} 1 \mathrm{Zr}$ were used. Prior to the determination of the weldability range, they were milled to achieve a truncated electrode geometry with the designation B0-16-2050-6-36. Table 2 shows the welding parameters. To determine the welding current range, a procedure, described in SEP 1220-2 was used [39]. In general, it is the current welding $(\Delta I)$ range, the difference between the welding current required to produce a minimum weld spot diameter $\left(I_{\min }\right)$ and the current $\left(I_{\max }\right)$, that caused the expulsion of liquid metal $[39,40]$. The minimum weld spot diameter, e.g. chisel test $(d-$ wmin), was defined as $4 \sqrt{ } t$, where $t$ is the sheet thickness [39].
For specimens welded with $I_{\min }$ and $I_{\max }$, cross-sections were prepared to measure the nugget width.

A detailed description of the applied determination of the welding range is given in the following. Starting with a welding current of $4.0 \mathrm{kA}$, two welds were performed per current setting [39]. If at least one of them was expulsion-free, the current was increased by $0.2 \mathrm{kA}$, and two more welds were made [39]. This procedure was repeated until the current setting $\left(I_{\mathrm{u}}\right)$ was reached, in which both generated welds had an expulsion [39]. Afterwards, the welding current was reduced by a current of $0.1 \mathrm{kA}$ until three expulsion-free welds could be produced at one current level. The welding current at which this was possible was determined as $I_{\max }$ defined [39]. The range above $I_{\max }$ is defined as the unstable region, where welds can occur with or without an expulsion.

\subsection{Analysis of the electrode displacement}

\subsubsection{Displacement monitoring system}

For the development of a force profile, the relationship between the adjusted force and the stiffness, i.e. displacement signal, must be analysed. Figure 4 left panel shows the relationship between the electrode force and the measured electrode displacement without a workpiece.

Figure 4 shows that there is a linear relationship between the applied electrode force and the electrode displacement. The stiffness of the system can be determined, as well as a correction between the electrode force and the electrode displacement. Figure 4 right panel illustrates the dependence between the set force and measured force value. The coefficient of determination between actual and reference force value is $R^{2}=99.9$, which represents a high accuracy of the adjusted force value.
Table 2 Welding parameters according to SEP 1220-2

\begin{tabular}{lllll}
\hline $\begin{array}{l}\text { Squeeze time } \\
(\mathrm{ms})\end{array}$ & $\begin{array}{l}\text { Welding time } \\
(\mathrm{ms})\end{array}$ & $\begin{array}{l}\text { Holding time } \\
(\mathrm{ms})\end{array}$ & $\begin{array}{l}\text { Electrode force } \\
(\mathrm{kN})\end{array}$ & $\begin{array}{l}\text { Electrode shape acc. to DIN EN ISO } \\
5821: 2010-04\end{array}$ \\
\hline 300 & 380 & 200 & 4.5 & B0-16-20-50-6-36 \\
\hline
\end{tabular}


Fig. 4 Left: Measurement of electrode force and the influence on the electrode displacement. Right: Determination between actual and reference force value

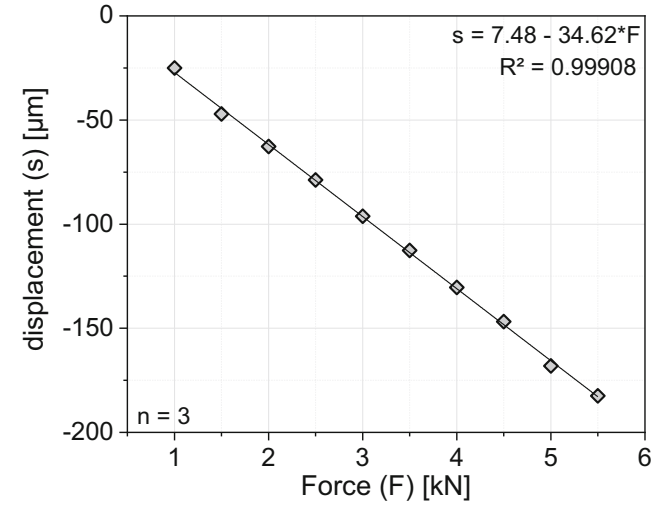

\subsubsection{Determination of characteristic values}

The aim of the analysis of the recorded process data is the identification of characteristic values for the design of force profiles. Based on the literature review, it can be seen that the electrode displacement is a significant reference parameter. For this reason, the electrode displacement signal is described and analysed below.

Figure 5 left panel shows a characteristic curve of the electrode displacement during the welding process. As an example, characteristic values during the welding time are defined in the detail view in Fig. 5 right panel. The expansion of the material due to Joule heating leads to a vertical displacement of the upper electrode and can be divided into two regions. Within the first region, the electrode displacement reaches a maximum described as $s_{\max }$ at time $t_{\max }$. After exceeding this maximum, the electrodes begin to sink into the material in the second region. The delta of the electrode displacement between the time of the displacement maximum and the end of the welding time is defined as $\Delta s$. The rate of expansion $v_{\exp }$ is the quotient of the maximum electrode displacement at the time of the maximum and is assumed to be linear. The indentation rate $v_{\text {ind }}$ is determined by the quotient of $\Delta s$ and $\Delta t_{\mathrm{s}}$ and is considered to be linear. In case of an expulsion, the point of time is automatically detected and analysed. In addition, the process variables' welding current and voltage are used to determine the total energy at the time $t_{\max }$. The aim of the analysis of the recorded process data is the identification of characteristic values for the design of force profiles. Based on the literature review, it can be seen that the electrode displacement is a significant reference parameter.

\section{Results}

\subsection{Initial condition}

The initial condition was determined according to the parameters of the SEP 1220-2. During the evaluation, an unstable range was defined in addition to the welding range. This describes the part of a welding range diagram in which expulsion can arise in a non-reproducible way. It is a special characteristic of press-hardened components and does not occur with galvanised steel grades. Figure 6 shows the measured welding range of the reference parameters.
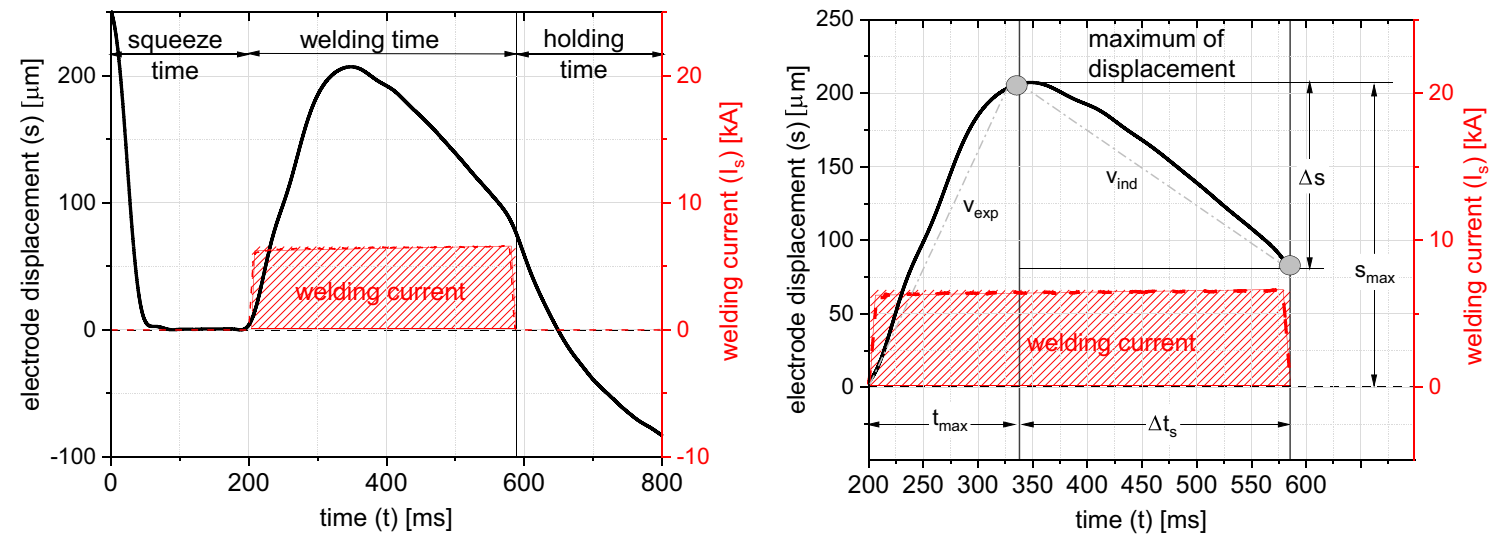

Fig. 5 Left: Displacement of the upper electrode over the whole welding process. Right: Characteristic points of the electrode displacement during the welding time, according to Killian et al. [41] 
Fig. 6 Welding range of the reference welding range based on the SEP 1220-2 for a joint of the similar material $(22 \mathrm{MnB} 5+$ AS150), acc. to [42]
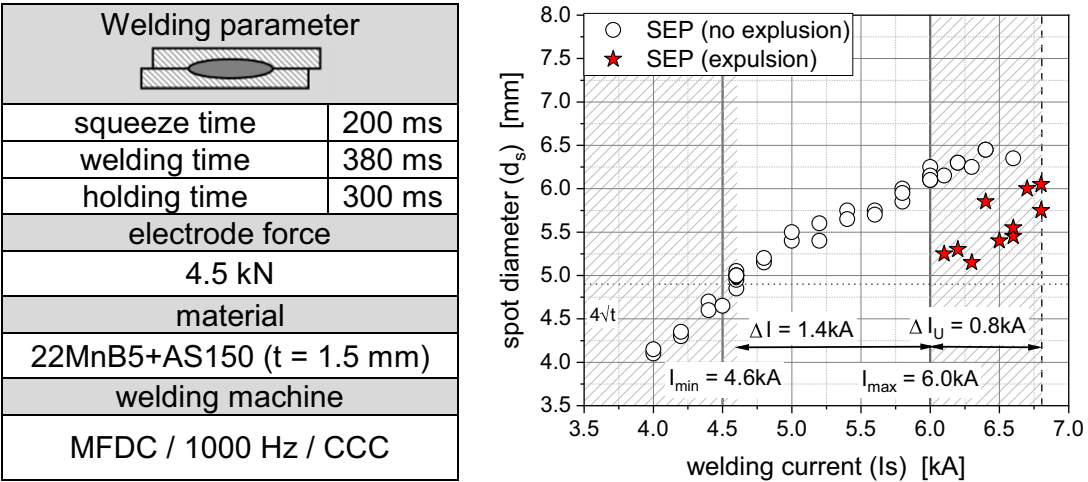

The result shows that the minimum spot diameter of $4.9 \mathrm{~mm}$ is achieved at a welding current of $4.6 \mathrm{kA}$. The maximum welding current is reached at $6.0 \mathrm{kA}$, where the welding specimens have an average spot diameter of $6.2 \mathrm{~mm}$. Therefore, a welding range $(\Delta I)$ of $1.4 \mathrm{kA}$ and an unstable current range $\left(I_{\mathrm{U}}\right)$ of $0.8 \mathrm{kA}$ was determined. In this unstable range, welds with and without expulsion can occur. In the following, the influence of different electrode force levels on the range of the welding range is examined.

\subsection{Influence of the electrode force on the welding range}

Figure 7 illustrates the determined welding ranges as a function of the selected constant electrode force of $2.5 \mathrm{kN}, 3.5 \mathrm{kN}$, $4.5 \mathrm{kN}$ and $5.5 \mathrm{kN}$. Each bar of the chart symbolises a welding range, as shown in Fig. 6.

It is obvious that by increasing the electrode force, the lower quality limit is shifted to higher welding currents. This fact can be explained by the relationship between the applied electrode force level and the resulting electrical resistance. As a result, an increasing electrode force results in a smaller amount of heat, which leads to a smaller spot diameter [14, 43]. Compared with the reference range, the upper-quality limit shifts to higher welding currents for a force level of 3.5 $\mathrm{kN}$. Contrary to the literature $[18,19]$, the risk of spattering
$\left(I_{\max }\right)$ increases with increasing electrode force at the same current, i.e. between the welding current ranges of $3.5 \mathrm{kN}$ and $5.5 \mathrm{kN}$. Expulsion occurs although the spot diameter decreases with increasing electrode force, $\mathrm{cf}$. nugget diameter of $I_{\max }$. Only the hypothesis of Davies could be an approach that with an increase in electrode force, the melt is squeezed out of the joining zone [17]. This hypothesis is discussed in more detail in Section 4.3.

The evaluation of the welding range analysis indicates that a variation of the electrode force between 2.5 and $5.5 \mathrm{kN}$ does not provide sufficient information for the design of the force profile. Therefore, the effect of a constant electrode force was investigated in an extended range from 2.0 to $6.0 \mathrm{kN}$. The purpose is to estimate the influence of the electrode force on the size of the spot diameter. It is expected that an increase in the spot diameter will result in low electrode forces because of the indirectly proportional relationship between force and electrical resistance. The results of this investigation confirm this hypothesis, as shown in Fig. 8. The quality limits of the welding range with $4.5 \mathrm{kN}$ were chosen as a reference.

With an electrode force below $4.5 \mathrm{kN}$, a minimum spot diameter (lower quality limit) is always reached for a welding current of $4.5 \mathrm{kA}$. It can be assumed that the required minimum spot diameter is already obtained at welding currents lower than $4.5 \mathrm{kA}$. Similarly, the same characteristic can be observed at the upper-quality limit of $5.9 \mathrm{kA}$. A reduction of
Fig. 7 Influence of different constant force levels of the welding range and nugget diameter, acc. to [42]

\begin{tabular}{|c|c|}
\hline \multicolumn{2}{|c|}{ Welding parameter } \\
\hline squeeze time & $200 \mathrm{~ms}$ \\
\hline welding time & $380 \mathrm{~ms}$ \\
\hline holding time & $300 \mathrm{~ms}$ \\
\hline electrode force (const.) \\
\hline $2.5 \mathrm{kN}, 3.5 \mathrm{kN}, 4.5 \mathrm{kN}, 5.5 \mathrm{kN}$ \\
\hline \multicolumn{2}{|c|}{ material } \\
\hline 22MnB5+AS150 ( $\mathrm{t}=1.5 \mathrm{~mm})$ \\
\hline \multicolumn{2}{|c|}{ welding machine } \\
\hline \multicolumn{2}{|c|}{ MFDC / $1000 \mathrm{~Hz} / \mathrm{CCC}$} \\
\hline
\end{tabular}


Fig. 8 Influence of the electrode force on the spot diameter for the electrode force range between 2.0 and $6.0 \mathrm{kN}$, acc. to [42]

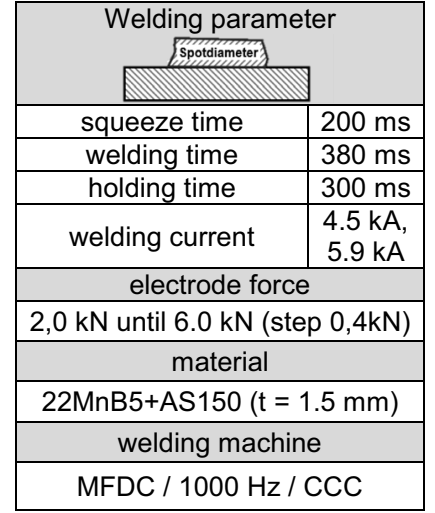

the electrode force leads to a significant increase in the spot diameters. It is expected that with three expulsion-free welds at the quality limits, an increase in the welding range compared with the reference can be assumed. This hypothesis is satisfied for all electrode forces in the range between 2.8 and $4.4 \mathrm{kN}$. At the force level of $2.4 \mathrm{kN}$, expulsion was detected at the lower quality limit. The same is displayed for the lowest electrode force of $2.0 \mathrm{kN}$ at the upper-quality limit. It can be concluded that welding without expulsion is not possible with electrode forces below $2.4 \mathrm{kN}$.

\subsection{Analysis of weld expulsion formation}

The requirements for the formation of expulsion are one of the unexplained phenomena of resistance spot welding, whose cause has so far only been approximated by theoretical considerations $[18,44]$. Based on process data analysis, it is intended to determine whether there is a correlation between the formation of expulsion and the characteristic values in the electrode displacement. A correlation between the time of expulsion and the time of the maximum displacement $t_{\max }$ was investigated. Figure 9 left panel shows an example of two welds with the same welding parameters, where one is expulsion-free and the other is an expulsion.

Both lines follow the same progression up to the time of expulsion. The cause of the expulsion cannot be determined from the graph. The comparison of the expulsion and the displacement maximum at $t_{\max }$ shows that expulsion occurred only after reaching the displacement maximum. This correlation is visualised of 127 expulsion welds in Fig. 9 right panel. The evaluation of the process data was carried out independently of the selected electrode force level. It is shown that the time of expulsion always formed after reaching the displacement maximum. The expansion of the welding nugget leads to an expansion of the electrodes up to the time $t_{\max }$. After the maximum is exceeded, this relationship reversed, and the electrodes sank more deeply into the softened material. This increased the external pressure on the welding nugget, which had to be compensated by the nugget. In this phase, the welding nugget and the welding process is highly sensitive to interfering effects, which increases the risk of expulsion.

In addition to the time correlation of the expansion maximum and the risk of expulsion, the process data were analysed with regard to the characteristic values maximum electrode displacement $\left(s_{\max }\right)$ and displacement delta $(\Delta s)$, as shown in Fig. 10.

The development of the maximum displacement (Fig. 10 left panel) indicated that the maximum increases in proportion to the welding current and approaches a limit value for expulsion (approx. $180 \mu \mathrm{m}$ ). As a result of a continuous current increase, the maximum electrode displacement rise and the welding process begins to become unstable. The unstable
Fig. 9 Left: Comparison of the electrode displacement during the welding time of an expulsion-free and a spattered weld with the same welding parameters [42]. Right: Overview of the chronological occurrence of displacement maxima and expulsion, welding signals are used from the experiments shown in Fig. 7
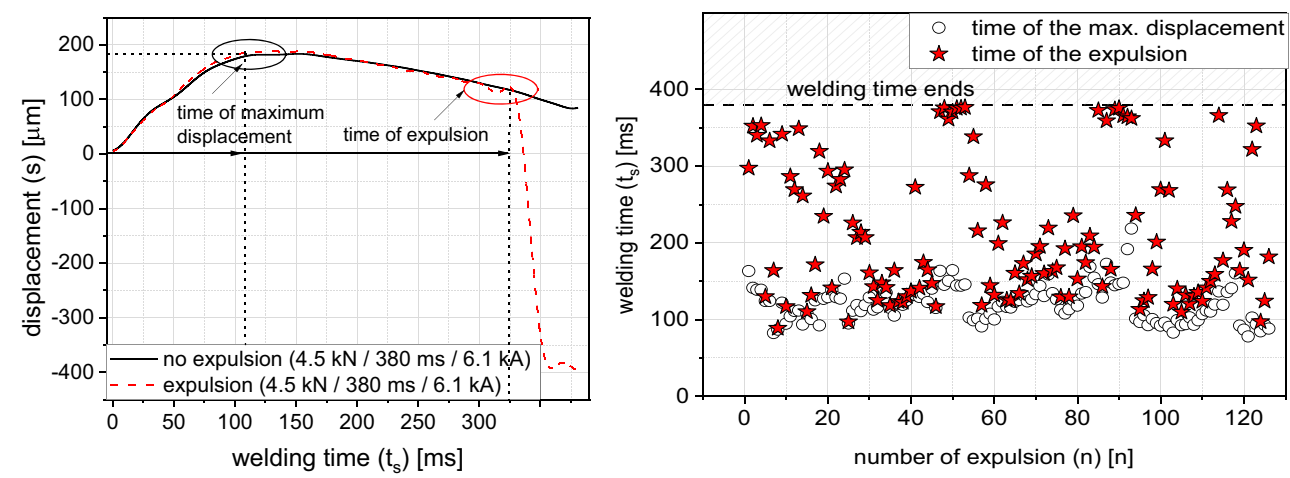
Fig. 10 Left: Influence of the maximum displacement $\left(s_{\max }\right)$. Right: Influence of displacement delta $(\Delta s)$ on the formation of expulsion for constant electrode forces of $3.5 \mathrm{kN}, 4.5 \mathrm{kN}$ and 5.5 $\mathrm{kN}$, acc. to [42]

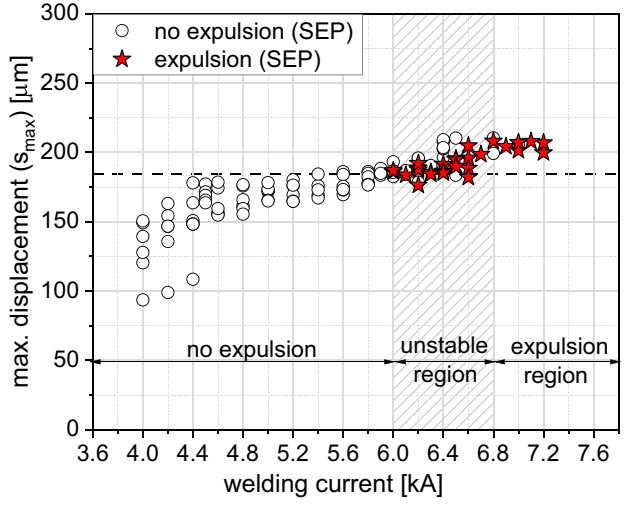

range in the welding range is also detectable. The same relationship can be observed in the sinking characteristics of the electrodes. If a delta is exceeded a limit during the sinking movement, expulsion formation is very probable.

From this correlation, the hypothesis can be derived that an unstable process behaviour arises, when the maximum electrode displacement and significant displacement delta exceeds an upper limit value. It is also noticeable that the plotted limit value of the maximum electrode displacement and the displacement delta are very close to each other. The hypothesis can be specified by assuming that expulsion occurs when the previous expansion is fully compensated by the indentation of the electrodes. Considering, the determined welding ranges can also be explained in more detail. To achieve a specific displacement delta, higher welding currents are required for welding with low electrode forces. Thus, the upper-quality limit of the welding range is shifted upwards by low electrode forces and the achievable spot diameter increases.

\subsection{Design of a theoretical force profile}

By the previously determined results, an appropriate force profile has been developed, which allows an increase in the welding range. The following restrictions for the design of a force profile must be observed:

- The electrode force at the beginning of the current input must ensure a high energy input in order to initiate early nugget formation.

- The selected electrode force should be within $2.5 \mathrm{kN}$ and $4.5 \mathrm{kN}$.

- After reaching the maximum displacement, a degressive force level is recommended that does not fall below the value of $2.5 \mathrm{kN}$ at any time.

- The processed signal of the electrode movement must be used in the design.

Figure 11 shows the theoretical approach for designing a force profile for the press-hardened 22MnB5 with aluminiumsilicon coating.

The welding process is separated into two phases: first, the phase of material heating and second the phase of the nugget formation and its growth.

In the phase of heating, the high energy input into the material must take place, and a uniform contact surface between the electrode and sheet metal must be achieved. Thus, a low electrode force is used first to achieve fast heating of the
Fig. 11 Theoretical model for the development of a force profile, acc. to [42]

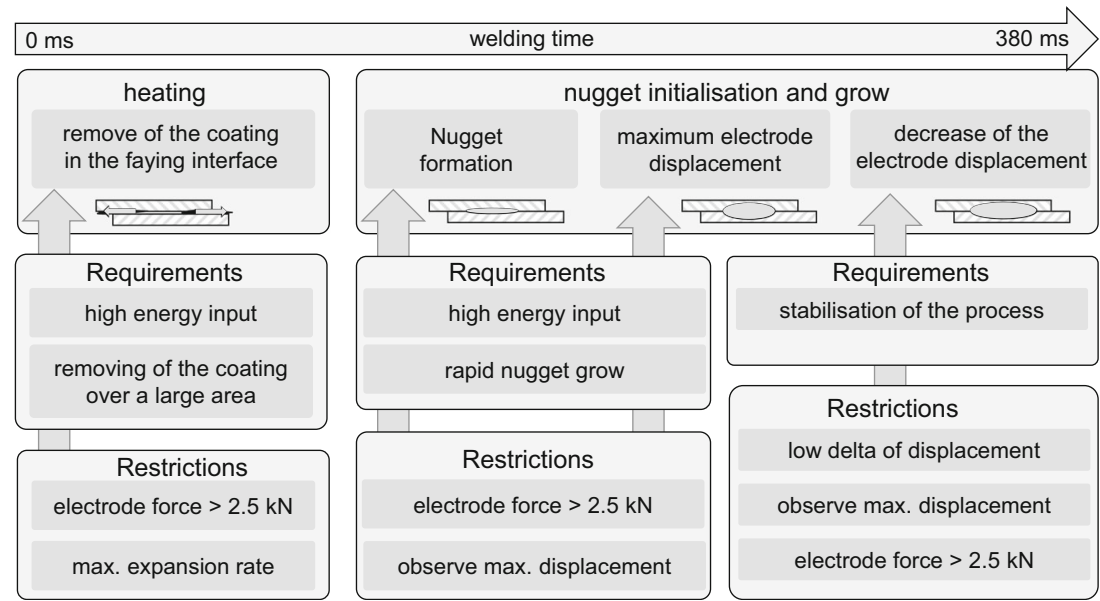


material to remove the coating over a large area in the faying interfaces. With the beginning of the nugget formation, a high energy input must be ensured, which supports rapid nugget growth. The nugget formation can be detected by the electrode displacement and the dynamic resistance signal $[28,45]$. The maximum electrode displacement is reached when the expansion rate slows down, and a turning point in the displacement signal is formed. The material begins to soften, and the electrodes start to sink into the material (displacement delta). In this phase, it is essential to stabilise the welding process, especially at high welding currents, to minimise the indentation of the electrodes. For this purpose, the electrode force has to be degressive, but must not fall below $2.4 \mathrm{kN}$. By progressively reducing the electrode force, a high current density is sustained, thereby increasing the energy input.

\subsection{Modelling a variable electrode force profile}

The upper-quality limit $\left(I_{\max }\right)$ of the SEP reference range is used to design the force profile. Figure 12 shows the electrode displacement and the dynamic resistance at a welding current of $6.0 \mathrm{kA}$.

It is shown that the nugget was formed in the time between 35 and $50 \mathrm{~ms}$ (dotted lines), according to [28, 45]. In the process of the electrode displacement, the maximum displacement is reached at a welding time of about $120 \mathrm{~ms}$ (dotted line). Subsequently, the electrode displacement stagnates for $30 \mathrm{~ms}$ and then drops down. To stabilise the welding process, the maximum displacement and the sinking displacement must be reduced. In the following, the force profile is determined from the progression of the electrode displacement and dynamic resistance. Based on the theoretical consideration and SEP reference signals, a force profile was designed, as shown in Fig. 13.

In order to provide a basis for comparison with the reference parameter, the squeeze, welding and holding times were equal. During the squeeze time, an electrode force of $4.6 \mathrm{kN}$ is selected to provides an initial stabilisation of the dynamic resistance, according to [46]. In the phase of heating the material, i.e. in the first $50 \mathrm{~ms}$ of the current flow, a high energy input should be generated. For this purpose, the electrode force is set at $2.6 \mathrm{kN}$. The restriction of a minimum force of $2.5 \mathrm{kN}$ is thus respected. The electrode force is kept constant for $25 \mathrm{~ms}$ because, in this time, the dynamic resistance reached the maximum and the largest amount of heat is generated (cf. Fig. 12, red circle). Until the nugget is developed $(50 \mathrm{~ms})$, the force is increased to replace the aluminium-silicon coating over a large area (faying interface). By the time of nugget initiation, after approximately $50 \mathrm{~ms}$, the electrode force is increased to $3.6 \mathrm{kN}$. Subsequently, the electrode force is degressive until the current is switched off to decrease the sinking of the displacement curve.

\subsection{Solution for an extended welding range}

For the realisation of the force profile, the upper-quality limit $\left(I_{\max }\right)$ of the reference welding range is compared with the designed force profile. Figure 14 illustrates the measured force curves of the initial condition and the optimised force profile. For both conditions, the same welding currents of $6.0 \mathrm{kA}$ and welding times of $380 \mathrm{~ms}$ were used.

Figure 14 right panel shows the SEP1220-2 parameter with a constant force of $4.5 \mathrm{kN}$. For this case, the applied force shows only a marginal variation of $50 \mathrm{~N}$. Also, the theoretical force profile is precisely reproduced by the force unit of the welding machine. The applied force values and times were selected to ensure the restrictions to design a force profile from Section 4.4 compares the initial state with the optimised force profile for electrode displacement, dynamic resistance and the total energy (Fig. 15).

The nugget formation can be detected by the electrode displacement and the dynamic resistance signal [22] (1). It
Fig. 12 Upper-quality limit $\left(I_{\max }\right)$ of the SEP reference SEP1220-2 with a force of $4.5 \mathrm{kN}$. Left: Displacement. Right: Dynamic resistance and total power input, acc. to $[42]$
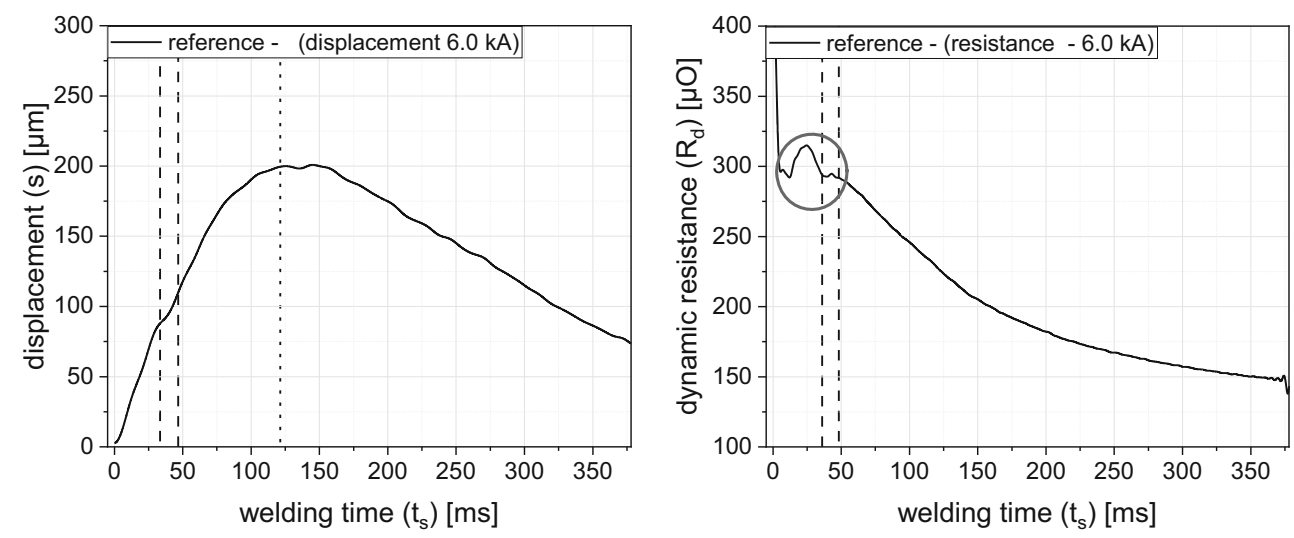
Fig. 13 Force profile based on the theoretical model, acc. to [42]
Fig. 14 Comparison of the recorded welding parameters. Left: Initial condition. Right: Optimised force profile at a current of $6.0 \mathrm{kA}$
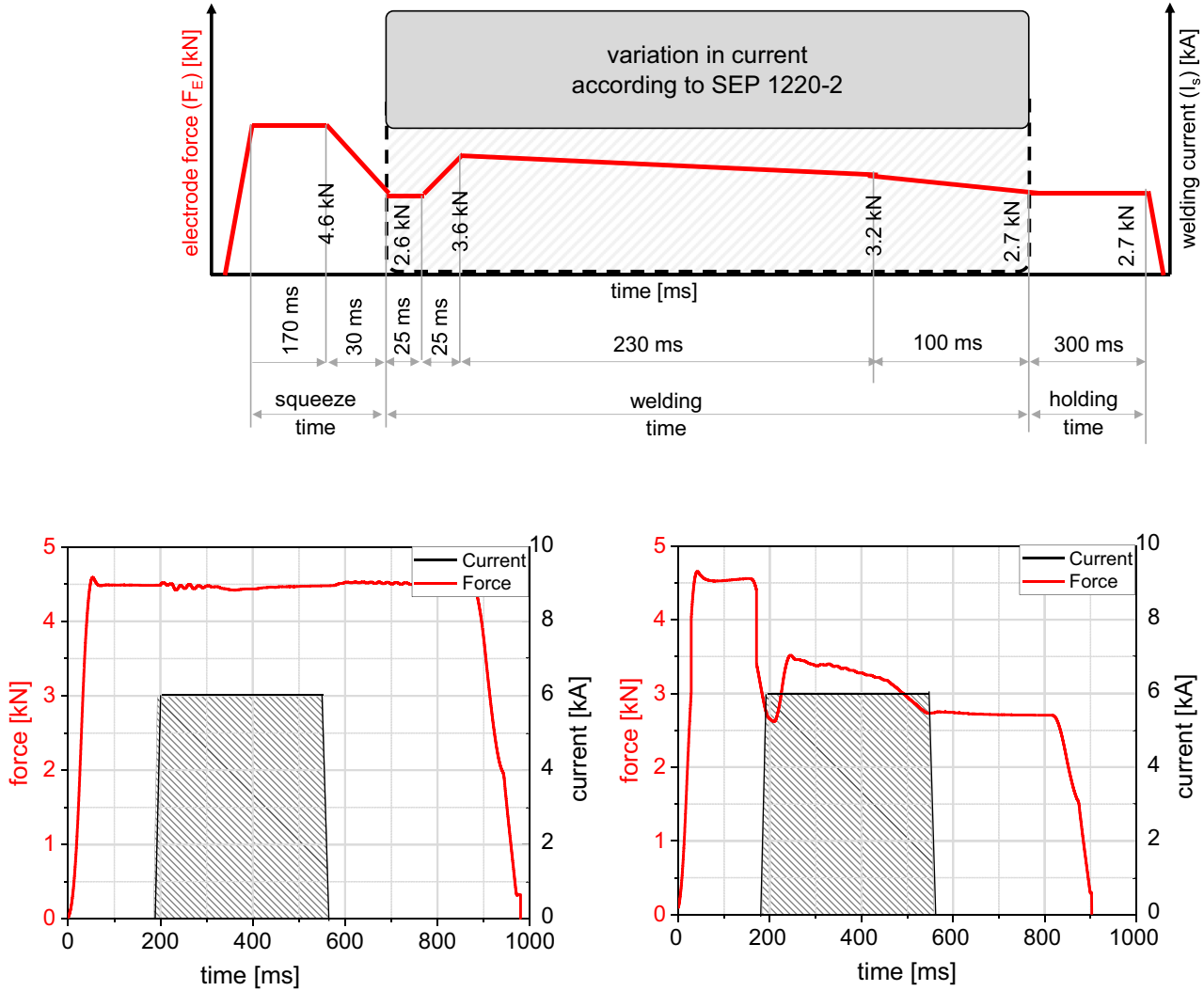

can be detected that an earlier nugget formation takes place in the electrode force profile. The displacement shows that a lower displacement maximum is reached by using the force profile (2). Furthermore, after reaching the displacement maximum, the applied digressive force compensated the sinking movement of the electrode into the material (3). The maximum displacement is correlated to a rapid power decrease in the faying interface (4). At the end of the welding time, the dynamic resistance is slightly above the reference at the same welding current (5). Also, nugget cross-sections were created with respect to welding time and force changes, as shown in Fig. 16.
Figure 16 shows that the force profile removes the coating in the faying interface over a larger area, as well as an earlier nugget initialisation starts $(36 \mathrm{~ms})$. As a result of the reduced electrode force, higher vertical growth of the welding nugget is visible $(60 \mathrm{~ms})$. At a welding time of $380 \mathrm{~ms}$, the nugget width is smaller of the force profile compared with the reference. According to Zhang et al. [21], a maximum nugget width can be achieved depending on the electrode face diameter. This leads to the conclusion that the force profile needs a higher welding current until the maximum nugget diameter is achieved. Figure 17 compares the determined welding ranges for the force profile and the reference. The force profile has an
Fig. 15 Comparison of the initial condition and the force profile at a welding current of $6.0 \mathrm{kA}$. Left: Graph of electrode displacement and partial power in the fayer interface (sheet/sheet). Right: Dynamic resistance and total energy input
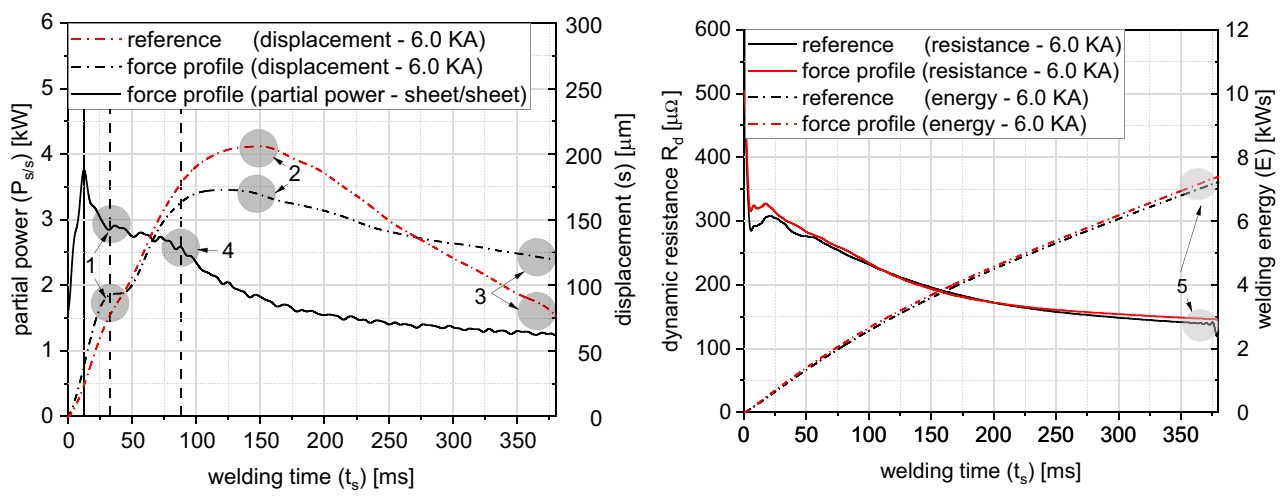


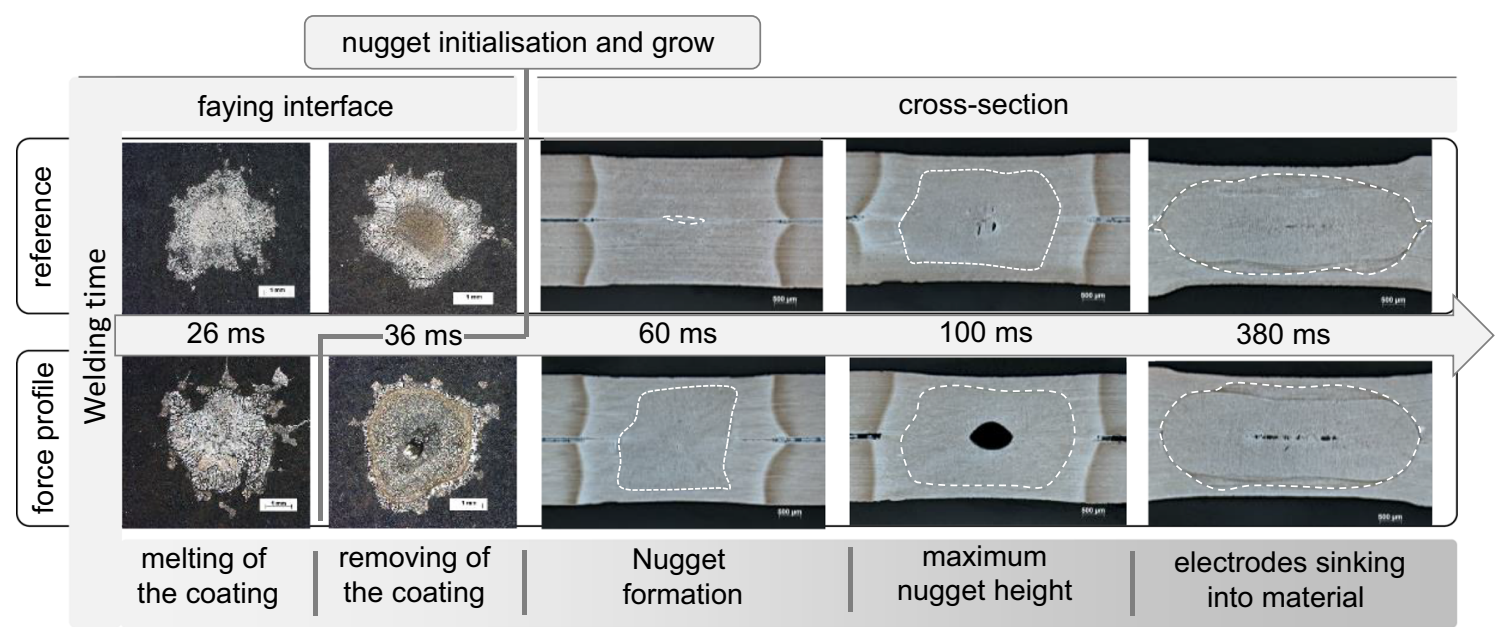

Fig. 16 Comparison between the reference and the force profile, cross-sections with respect to welding time, welding current of $6.0 \mathrm{kA}$

Fig. 17 Determined welding range with force profile and the reference with a constant force level of $3.1 \mathrm{kN}$ and $4.5 \mathrm{kN}$, acc. to [42]

\begin{tabular}{|c|c|}
\hline \multicolumn{2}{|c|}{ Welding parameter } \\
\hline impulse & 1 \\
\hline squeeze time & $200 \mathrm{~ms}$ \\
\hline welding time & $380 \mathrm{~ms}$ \\
\hline holding time & $300 \mathrm{~ms}$ \\
\hline electrode force \\
\hline $\begin{array}{c}\text { force profile }(3,1 \mathrm{kN}), \\
3,1 \mathrm{kN}, 4,5 \mathrm{kN}\end{array}$ \\
\hline \multicolumn{2}{|c|}{ Material } \\
\hline 22MnB5+AS150 $(\mathrm{t}=1.5 \mathrm{~mm})$ \\
\hline welding machine \\
\hline MFDC / $1000 \mathrm{~Hz} / \mathrm{CCC}$ \\
\hline
\end{tabular}

average electrode force of $3.1 \mathrm{kN}$ during the welding time, which was used as a corresponding constant force parameter.

The largest welding range of $3.0 \mathrm{kA}$ is achieved with the force profile. At the constant electrode forces of $3.1 \mathrm{kN}$ and $4.5 \mathrm{kN}$, the welding range is reduced to $2.3 \mathrm{kA}$ and $1.4 \mathrm{kA}$ respectively. In addition to increased process reliability, the electrode force profile also leads to an increase in the nugget diameters. The determined nugget diameters at the upper current limit are $7.0 \mathrm{~mm}$ for the force profile, $6.7 \mathrm{~mm}$ for an electrode force of $3.1 \mathrm{kN}$ and $6.0 \mathrm{~mm}$ for a force of $4.5 \mathrm{kN}$.
In addition, the tensile shear forces were determined at the welding range limit (Fig. 18).

At the lower current limits $\left(I_{\min }\right)$, the maximum tensile shear forces are between 15.3 and $17.8 \mathrm{kN}$. The lowest tensile force is achieved in the force profile. It can be explained that the average spot diameter is smaller than in the other performed tests. Smaller spot diameter is due to the subsequent welding of the shear tensile specimens after the welding range determination. As a result, there is a difference in spot diameter of $\pm 0.1 \mathrm{~mm}$ compared with the welding range.
Fig. 18 Determined tensile shear force for the force profile and the reference with a constant force level of $3.1 \mathrm{kN}$ and $4.5 \mathrm{kN}$, acc. to [42]
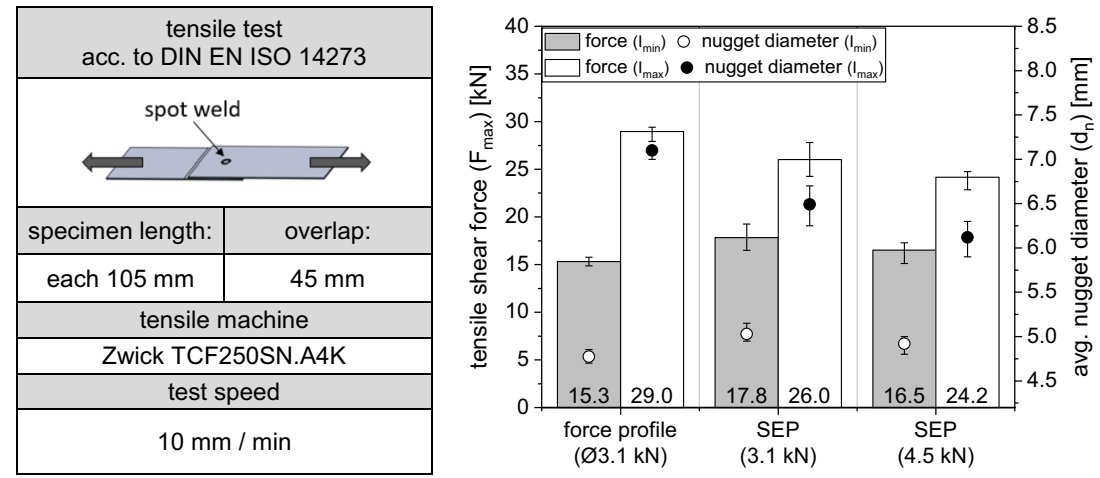
Consequently, the weld spot has a reduced cross-sectional area, which reduces the shearing force of the specimen.

At the upper current limits $\left(I_{\max }\right)$, the maximum shear tensile forces are between 24.2 and $29.0 \mathrm{kN}$. Also, the maximum shear tensile force is influenced by the diameter of the spot. In the case of the force profile, the average point diameter is around $7.1 \mathrm{~mm}$, while by the constant electrode force of 3.1 $\mathrm{kN}$ and $4.5 \mathrm{kN}$, the average point diameters are $6.5 \mathrm{~mm}$ and $6.1 \mathrm{~mm}$.

\section{Conclusion}

For the analytical compilation of a force profile, characteristic values were extracted from the process analysis, which allows the prediction of the formation of expulsion. It was demonstrated that the electrode displacement is suitable as a control variable for the design of a force profile. By a detailed observation of the electrode displacement, it is possible to estimate the resulting welding range for $22 \mathrm{MnB} 5+\mathrm{AS} 150$. The analysis showed that when a specific sinking displacement was exceeded, an increased spatter formation occurred. The applied approach is based on the compensation of the sinking of the electrodes by a specific reduction of the electrode force, which led to a process stabilisation. In addition, the maximum expansion of the electrode displacement must be limited. Furthermore, it has to be considered that after reaching the maximum electrode displacement, the force level should only decrease to increase the process stability. Also, after reaching the maximum electrode displacement, the force level should only decrease to improve the process stability. Comparing the force profile $(\varnothing 3.1 \mathrm{kN})$ to the initial state (SEP1220-2), the welding current range could be increased from 1.2 to 3.0 $\mathrm{kA}$. If only the influence of an electrode force is considered, it is shown that even with a constant electrode force of $3.1 \mathrm{kN}$, a welding current range of $2.3 \mathrm{kA}$ could be produced. Consequently, it must be clarified whether the force profile can achieve an improvement of the welding current range under industrial conditions. In further work, the results will be investigated on poor fit-up conditions and other materials.

Acknowledgements Open Access funding enabled and organized by Projekt DEAL.

Open Access This article is licensed under a Creative Commons Attribution 4.0 International License, which permits use, sharing, adaptation, distribution and reproduction in any medium or format, as long as you give appropriate credit to the original author(s) and the source, provide a link to the Creative Commons licence, and indicate if changes were made. The images or other third party material in this article are included in the article's Creative Commons licence, unless indicated otherwise in a credit line to the material. If material is not included in the article's Creative Commons licence and your intended use is not permitted by statutory regulation or exceeds the permitted use, you will need to obtain permission directly from the copyright holder. To view a copy of this licence, visit http://creativecommons.org/licenses/by/4.0/.

\section{References}

1. Peterson W, Pakalnins E, Carpenter JA (2004) Long life electrodes for resistance spot welding of aluminium sheet alloys and coated high strength steel sheet. FY Progress Report: 229-236

2. Hou Z, Kim I-S, Wang Y, Li C, Chen C (2007) Finite element analysis for the mechanical features of resistance spot welding process. J Mater Process Technol 185:160-165. https://doi.org/10. 1016/j.jmatprotec.2006.03.143

3. DVS - Deutscher Verband für Schweißen (ed) (2017) DVSTechnikreport 2017: Organisation und Schwerpunktthemen der Abteilung "Forschung und Technik" im DVS. DVS Media $\mathrm{GmbH}$, Düsseldorf

4. Scotchmer N (2007) Widening the welding lobe of advanced high strength steels in the resistance spot welding process: research project report. Huys Industries Limited

5. Hwang IS, Kang MJ, Kim DC (2011) Expulsion reduction in resistance spot welding by controlling of welding current waveform. Procedia Eng 10:2775-2781. https://doi.org/10.1016/j.proeng. 2011.04.461

6. Billur E (ed) (2019) Hot stamping of ultra high-strength steels: from a technological and business perspective. Springer International Publishing, Cham

7. Lanzerath H, Tuerk M (2015) Lightweight potential of ultra high strength steel tubular body structures. SAE Int J Mater Manf 8:813822. https://doi.org/10.4271/2015-01-0570

8. Saha DC, Ji CW, Park YD (2015) Coating behaviour and nugget formation during resistance welding of hot forming steels. Sci Technol Weld Join 20:708-720. https://doi.org/10.1179/ 1362171815Y.0000000054

9. Choi H-S, Park G-H, Lim W-S, Kim BM (2011) Evaluation of weldability for resistance spot welded single-lap joint between GA780DP and hot-stamped 22MnB5 steel sheets. J Mech Sci Technol 25:1543-1550. https://doi.org/10.1007/s12206-0110408-x

10. Ji C-W, Jo I, Lee H, Choi ID, do Kim Y, Park YD (2014) Effects of surface coating on weld growth of resistance spot-welded hotstamped boron steels. J Mech Sci Technol 28:4761-4769. https:// doi.org/10.1007/s12206-014-1043-0

11. Sun HT, Lai XM, Zhang YS, Shen J (2007) Effect of variable electrode force on weld quality in resistance spot welding. Sci Technol Weld Join 12:688-696. https://doi.org/10.1179/ $174329307 X 251862$

12. Choi H-S, B-m K, Park G-H et al (2010) Optimisation of resistance spot weld condition for single lap joint of hot stamped 22MnB5 by taking heating temperature and heating time into consideration. Trans Korean Soc Mech Eng A 34:1367-1375. https://doi.org/10. 3795/KSME-A.2010.34.10.1367

13. Mikno Z, Kowieski S, Zhang W (2016) Simulation and optimisation of resistance welding using the SORPAS ${ }^{\circledR}$ software programme. eBIS. https://doi.org/10.17729/ebis.2016.4/2

14. Kobayashi T, Mihara Y (2014) Numerical simulation of nugget formation in spot welding: Mechanical Design \& Analysis Corporation. SIMULIA Community Conference 2014:1-15

15. Tang H, Hou W, Hu SJ (2002) Forging force in resistance spot welding. Proceedings of the Institution of Mechanical Engineers, Part B: Journal of Engineering Manufacture 216:957-968. https:// doi.org/10.1243/09544050260174166

16. Schmiedgen D (1968) Schweißlinsenbildung beim WiderstandsPunktschweißen und deren Beeinflussung durch den 
Kontaktwiderstand. Technical University of Dresden (Germany), PhD-Thesis, 1968

17. Davies AC (1993) The science and practice of welding, 10th edn. Cambridge Univ. Press, Cambridge

18. Zhang H (1999) Expulsion and its influence on weld quality. Weld J 78:373-380

19. Zhang H, Hu SJ, Senkara J, Cheng S (2000) A statistical analysis of expulsion limits in resistance spot welding. J Manuf Sci Eng 122: 501-510. https://doi.org/10.1115/1.1285873

20. Williams NT, Parker JD (2013) Review of resistance spot welding of steel sheets Part 2 Factors influencing electrode life. Int Mater Rev 49:77-108. https://doi.org/10.1179/095066004225010541

21. Zhang Y, Shen J, Lai X (2012) Influence of electrode force on weld expulsion in resistance spot welding of dual phase steel with initial gap using simulation and experimental method. ISIJ Int 52:493498. https://doi.org/10.2355/isijinternational.52.493

22. Chien C-S, Kannatey-Asibu E Jr (2002) Investigation of monitoring systems for resistance spot welding. Weld J 81:195-199

23. Tang H, Hou W, Hu SJ, Zhang HY et al (2003) Influence of welding machine mechanical characteristics on the resistance spot welding process and weld quality. Weld J 82:116-125

24. Tang H, Hou W, Hu JS et al (2000) Force characterisitcs of resistance spot welding of steels. Weld J 79:175-184

25. S-s A, Luo Z, X-x T et al (2009) Study on quality of resistance spot welded aluminum alloys under various electrode pressures. Front Mater Sci China 3:98-101. https://doi.org/10.1007/s11706-0090004-5

26. Kuban J, Stefanek A, Dzuranyi E (1989) Control and inspection systems for resistance welding. Weld Int 3:1003-1006. https://doi. org/10.1080/09507118909449070

27. Tsai CL, Dai WL, Dickinson DW (1991) Analysis and development of a real-time control methodology in resistance spot welding. Weld J 70:339-351. https://doi.org/10.4271/910191

28. Gedeon SA, Sorensen CD, Ulrich KT et al (1987) Measurement of dynamic electrical and mechanical properties of resistance spot welds: displacement curves and dynamic resistance provide significant data for evaluating nugget quality. Weld J 66:378-385

29. Podrzaj P, Simoncic S Welding force as a variable in resistance spot welding control. In: 2013 2nd International Conference on Measurement, Information and Control (ICMIC), pp 818-821

30. Dickinson DW, Franklin JE, Stanya A (1980) Characterisation of spot welding behavior by dynamic electrical parameter monitoring. Weld J 59:170-176

31. Waller DN, Knowlson PM (1965) Electrode separation applied to quality control in resistance welding. Weld J 44:168-174

32. Janota M (1974) The relationship between thermal expansion and the growth of a resistance spot weld. Proceedings of the Third
International Conference on Advances in Welding Processes, Harrogate, 21-26

33. Zhang P, Zhang H, Chen J, Ma Y (2007) Quality monitoring of resistance spot welding based on electrode displacement characteristics analysis. Front Mech Eng China 2:330-335. https://doi.org/ 10.1007/s11465-007-0058-y

34. Roberts WL (1951) Resistance variations during spot welding. Weld J 30:1004-1019

35. Waller DN (1964) Head movement as a means of resistance welding quality control. Br Weld J 11:118-122

36. Taylor JL, Xie P (1987) A new apprach to the displacement monitor in resistance spot welding of mild steel sheet. Metal Construction 19:72-75

37. Johnson KI, Needham JC (1972) New design of resistance spot welding machine for quality control. Weld J 51:122-131

38. Kuban J, Janota M (1976) Regelung von Punktschweißmaschinen durch Ausdehnungsmessung. ZIS-Mitteilungen 18:346-356

39. Deutsches Institut für Normung e.V. (2011) Testing and documentation guideline for the joinability of thin sheet of steel- Part 2: Resistance Spot Welding(1220-2)

40. Tumuluru M (2007) The effect of coatings on the resistance spot welding behavior of $780 \mathrm{MPa}$ dual-phase steel. Weld J 86:161-169

41. Killian ML, Orr MD (22.12.) Inter-electrode displacement monitoring and control. Ohio State University Research Foundation(US005558785A)

42. Wohner M (2017) Untersuchung des Effektes einer variablen Elektrodenkraft auf die Schweißqualität beim Widerstandspunktschweißen. own Master-Thesis, GRIN Publishing GmbH, München, Germany

43. Zhou K, Cai L (2014) Study on effect of electrode force on resistance spot welding process. J Appl Phys 116:84902. https://doi.org/ $10.1063 / 1.4893968$

44. Senkara J, Zhang H, Hu SJ (2004) Expulsion prediction in resistance spot welding. Weld J 83:123-132

45. Ighodaro OL-R, Biro E, Zhou YN (2017) Study and applications of dynamic resistance profiles during resistance spot welding of coated hot-stamping steels. Metall and Mat Trans A 48:745-758. https://doi.org/10.1007/s11661-016-3899-3

46. Petzold J (1970) Untersuchungen zur Erhöhung der Elektrodenstandzeit beim Punktschweißen verzinkter Feinbleche durch widerstandsabhängige Prozeßregelung. Technical University of Aachen (Germany), PhD-Thesis, 1970

Publisher's note Springer Nature remains neutral with regard to jurisdictional claims in published maps and institutional affiliations. 